\title{
The combination of an oxygen-dependent degradation domain-regulated adenovirus expressing the chemokine RANTES/CCL5 and NK-92 cells exerts enhanced antitumor activity in hepatocellular carcinoma
}

\author{
JIANG LI, HUI LIU, LINFANG LI, HONGPING WU, CHUNHONG WANG, ZI YAN, YING WANG, \\ CHANGQING SU, HUAJUN JIN, FUPING ZHOU, MENGCHAO WU and QIJUN QIAN \\ Laboratory of Viral and Gene Therapy, Eastern Hepatobiliary Surgical Hospital and Institute, \\ The Second Military Medical University, Shanghai 200438, P.R. China
}

Received September 12, 2012; Accepted November 30, 2012

DOI: $10.3892 /$ or.2012.2217

\begin{abstract}
Oncolytic adenoviruses are modified based on adenovirus serotype 5 (Ad5), which belongs to subgroup $C$ and depends on Coxsackie-adenovirus receptor (CAR) to recognize target cells. However, expression of CAR is generally low or lost in certain tumors including hepatocellular carcinoma (HCC). By contrast, CD46 is highly expressed in various types of malignant tumor cells. Therefore, we constructed an adenovirus vector expressing the human RANTES/CCL5 gene regulated by oxygen-dependent degradation domain (ODD) and analyzed its antitumor effects in vitro and in vivo. The human RANTES/CCL5 gene was fused with ODD by PCR and the recombinant oncolytic adenovirus containing RANTES-ODD, SG511-CCL5-ODD, was constructed by the Gateway system, which infected cells by binding CD46. Viral replication experiments were performed to evaluate the selective replication ability of SG511-CCL5-ODD. RANTES expression was determined by ELISA. The chemotactic test was used to analyze the ability of the expressed RANTES to recruit NK92 cells. The antitumor effects of SG511CCL5-ODD were examined in HCC xenografts in nude mice. A chimeric oncolytic adenovirus, SG511-CCL5-ODD, was constructed successfully. Cells infected with the recombinant virus were able to express RANTES selectively in different environments controlled by ODD and the expressed RANTES was able to recruit NK92 cells by its chemotactic effect in vitro and improve the anticancer immune response in $\mathrm{HCC}$ xenografts in nude mice. The chimeric adenovirus SG511-
\end{abstract}

Correspondence to: Professor Qijun Qian, Laboratory of Viral and Gene Therapy, Eastern Hepatobiliary Surgical Hospital and Institute, The Second Military Medical University, 225 Changhai Road, Shanghai 200438, P.R. China

E-mail: qianqj@sino-gene.cn

Key words: RANTES, adenovirus, hepatoma, gene therapy, adoptive immunotherapy
CCL5-ODD highly expressed the RANTES-ODD fusion gene in the hypoxia of HCC under the control of the ODD and effectively attracted NK92 cells and a high number of immunocytes. These factors had complementary advantages and, in combination, exerted enhanced antitumor efficacy.

\section{Introduction}

T cells provoke the antitumor immune response; therefore, $\mathrm{T}$ cellmediated immunotherapy is regarded as a crucial approach in cancer treatment. The adoptive cell transfer (ACT) combined with lymphodepletion has led to clinical tumor suppression in $50-70 \%$ of patients with metastatic melanoma (1). However, the large number of activated and expanded $\mathrm{T}$ cells required in the laboratory (more than $1 \times 10^{10}$ ) makes ACT a costly and laborintensive treatment (2-4).

Owing to the marked effects in the treatment of metastatic melanoma and the evident impact on cancer regression in approximately $50 \%$ of patients, development of ACT therapy utilizing autologous tumor-infiltrating lymphocytes (TIL) is gaining momentum $(5,6)$. In addition, although some ACT-treated patients achieved long-term survival, the majority experienced cancer relapse (7). Therefore, strategies aimed at improving the migration of $\mathrm{T}$ cells into tumor sites are likely to enhance the efficacy of ACT therapy.

Immune cells trafficking to inflammation sites are usually affected by chemokines. Through chemotaxis, cells that express appropriate chemokine receptors can migrate along with a chemokine gradient to specific tissues or infection sites (8). Chemokines also play an important role in T cell-mediated antitumor immune responses (9-11). A variety of immunocytes have strong chemotactic effects after being regulated upon the activation of normal T-cell expressed and secreted RANTES/CCL5 that chemotactically attracts a huge number of immunocytes to tumor tissues to exert antitumor efficacy (12-17).

As a result of immune response unable to eradicate tumor cells, cancer develops. There may be mechanisms significantly involved in tumor development, which allow tumor cells to escape immune surveillance from natural killer (NK) and other 
immune cells (18-20). NK cells represent distinct subsets of lymphoid cells with innate immune functions (21). NK cells are derived from the bone marrow, they circulate in the blood and then become activated by cytokines or upon encountering target cells expressing ligands for NK cell receptors (22). NK cells provide one of the first lines of defense against virusinfected and tumor cells. In general, no immune receptor gene rearrangement occurs in them and their cytotoxicity is not MHC-restricted. NK cells are able to mediate the spontaneous killing of various tumor cells without prior sensitization. To date, not all NK cell lines can be established from patients with large granular lymphoma (23) and, with regard to the in vitro tumoricidal properties, these NK cell lines show considerable differences, although some of them have been shown to maintain cytotoxicity $(23,24)$.

Isolated from peripheral lymphocytes of a non-Hodgkin's lymphoma patient in 1992 (25), NK-92 was successfully set up as a natural anti-IL-2 dependent cell line, with similar functional characteristics as human NK cells. Research demonstrated that NK-92 cells showed high cytotoxic activity against tumor cell lines from leukemia (26) and malignant melanoma (27). Additionally, in vivo application of NK-92 was tested in immune deficiency (SCID) mouse models, xenografted with patient-derived leukemia (T-ALL, AML) (24) or human malignant melanoma cell lines (27). Tumor burden was reduced or undetectable and the survival of mice was significantly improved. NK-92 cells are constantly being developed for adoptive immunotherapy in cancer treatment and have entered clinical trials (28).

The most widely-used oncolytic adenoviruses in cancer therapy are based on adenovirus serotype 5 (Ad5), which belongs to subgroup $\mathrm{C}$ and Coxsackie-adenovirus receptor (CAR) on target cells are necessary for successful transduction $(29,30)$. However, expression of CAR is generally low or lost in the process of the malignant progression of certain tumors, including hepatocellular carcinoma (HCC) (31-33), limiting the transduction of Ad5-based vectors in some tumor cells and resulting in impaired antitumor effects (31). By contrast, CD46, a cellular receptor for Ad11 (subgroup B) (34), is highly expressed in various types of malignant tumor cells including HCC cells (35-38). Therefore, to address the issue of CAR-dependent cell entry, novel fiber chimeric adenoviral vectors have recently been designed by switching the knob and shaft of the Ad5 fiber to those of the Ad11 fiber that can recognize the abundant CD46 receptor on tumor cells (39). Previous studies have indicated that viral entry and antitumor activity could be greatly improved by $5 / 11$ fiber chimeric oncolytic adenoviruses compared with Ad5-based viruses $(40,41)$. Nevertheless, the tumor-suppressing capacity of 5/11 fiber chimeric oncolytic adenoviruses in HCC have yet to be fully explored.

Genetic modification of signal pathways promoting cell growth and survival leads to the emergence of tumor cells, whose expansion depends on nutrient supply. Oxygen limitation is crucial for controlling angiogenesis, glucose metabolism, survival and tumor spread. This effect is orchestrated by hypoxia-inducible factor (HIF), a main transcriptional factor in nutrient stress signal. Variations in oxygen tension $\left(p_{O 2}\right)$ are not directly sensed by HIF but by a class of 2-oxoglutaratedependent and iron-dependent dioxygenases which belong to the family of non-haem oxidizing enzymes. Due to strict control of $p_{\mathrm{O}_{2}}$ to the activity, these enzymes are the true oxygensensing molecules controlling the hypoxic response. Two types of oxygen sensors control HIF action; the first are known as the prolyl hydroxylase domain (PHD) proteins. PHDs hydroxylate two prolyl residues (P402 and/or P564) in the human HIF-1a region considered the oxygen-dependent degradation domain (ODD). This HIF- $\alpha$ modification specifies rapid interaction with the tumor-suppressor protein von Hippel-Lindau (VHL), a component of an E3 ubiquitin ligase complex. As a result, HIF- $\alpha$ subunits are marked with polyubiquitin chains driving them to destruction by the proteasomal system. ODD is closely related to the rapid degradation of intracellular proteins (42). Some proteins with ODD display instability under normoxia, but stability under hypoxia. Hypoxia exists within most solid tumors (43-46). Hence, as a regulatory element, the translated ODD can lead to a concentration of certain proteins at a specific high level.

Therefore, we constructed a chimeric adenovirus SG511CCL5-ODD carrying RANTES-ODD fusion gene. We hypothesized that in hypoxia of HCC, RANTES is highly expressed under the control of ODD and attracts a large number of immunocytes to tumor tissues to exert antitumor efficacy. NK92 cells were also administered by tail vein injection and they can be attracted to the tumor site by RANTES. In the HCC tumor site, SG511-CCL5-ODD and NK92 cells jointly exerted an enhanced antitumor activity.

\section{Materials and methods}

Cell lines and culture. Human primary HCC cell lines Hep3B and SK-Hep-1 and human normal fibroblast cell lines BJ were purchased from the American Type Culture Collection (ATCC, Manassas, VA, USA). Human HCC cell lines, SMMC-7721, BEL-7404 and BEL-7405 and human normal hepatocellular cell lines L02 were obtained from the Institutes of Cell Biology, Chinese Academy of Sciences (Shanghai, China). The human embryonic kidney (HEK) 293 cell line was obtained from Microbix Biosystem, Inc. (Toronto, ON, Canada). NK-92 was purchased from the American Type Culture Collection, and was maintained in $\alpha$ medium (Gibco BRL, Gaithersburg, MD, USA) supplemented with $2 \mathrm{mM}$ L-glutamine, $0.2 \mathrm{mM}$ i-inositol, $20 \mathrm{mM}$ folic acid, $0.1 \mathrm{mM}$ 2-mercaptoethanol, $12.5 \%$ fetal bovine serum (FBS) and $12.5 \%$ horse serum containing 100 U human IL-2 (Sigma). L02, SMMC-7721, BEL-7404 and BEL-7405 were maintained in RPMI-1640 with $10 \%$ FBS and HEK293, SK-Hep-1 and Hep3B were maintained in Dulbecco's modified Eagle's medium (Gibco BRL) in a $5 \% \mathrm{CO}_{2}$ atmosphere at $37^{\circ} \mathrm{C}$, containing $10 \%$ FBS. BJ was maintained in modified Eagle's medium (Gibco BRL) in a $5 \% \mathrm{CO}_{2}$ atmosphere at $37^{\circ} \mathrm{C}$, containing $10 \% \mathrm{FBS}$. All media were supplemented with $100 \mathrm{U} / \mathrm{ml}$ penicillin and $100 \mu \mathrm{g} / \mathrm{ml}$ streptomycin. Hypoxic conditions $\left(1 \% \mathrm{O}_{2}\right)$ were achieved with a three-gas incubator (Thermo Scientific).

Construction of adenovirus. pCMV-SPORT6 vector containing human RANTES gene was purchased from Proteintech Group, Inc. Ad5/F11 mosaic adenovirus plasmids, pPE3-F11-ccdB, pSG500 (47), pPE3-F11, were modified in our lab. pPE3-F11 was constructed by switching the knob and shaft of the 
pBHGE3 (Microbix Biosystem) fiber to those of the Ad11 fiber. pPE3-F11-ccdB was inserted ccdB (ccdB is negative selection in E. coli following recombination and transformation) into E3 area of pPE3-F11. We used the primers 1-4 as follows: primer 1: CGGAATTCACCATGAAGGTCTCCG CGGCAG; primer 2: GCTAACATCTCCAAGTCTAAGCT CATCTCCAAAGAG; primer 3: GTCATCATCCATTGGGAT ATAGGGAGCTAACATCTCCAAG; primer 4: CGGGAT CCCTATAACTGGAAGTCATCATCCATTG. The RANTES gene and ODD domain were fused and amplified by overlapping PCR, in which the restriction endonuclease sites, EcoR I and $\operatorname{BamH} \mathrm{I}$, were introduced into the upstream and downstream of the fused gene. The PCR fragment was inserted into pENTR12 (Invitrogen) and pDC315 (Microbix). After confirming by sequencing, the generated plasmids were labeled as pENTR12-CCL5-ODD, pDC315-CCL5-ODD. pENTR12-CCL5-ODD was recombined with adenovirus backbone plasmid pPE3-F11-ccdB by Gateway recombination in DH5 $\alpha$; the generated adenovirus backbone vector was identified by restriction endonuclease digestion and labeled pPE3-F11-CCL5-ODD. Adenovirus shuttle plasmid pSG500 with Ela controlled by the hTERT promoter and Elb controlled by HRE was transfected together with pPE3-F11-CCL5-ODD into HEK293 cells by Lipofectamine 2000 reagent, to generate a tumor-selective proliferating adenovirus, SG511-CCL5-ODD. Plasmid pDC315-CCL5-ODD was transfected together with pPE3-F11 into HEK293 cells by Lipofectamine 2000 reagent, to generate a tumor-selective proliferating adenovirus, AD5/11-CCL5-ODD. The viral titers of SG511-CCL5-ODD and AD5/11-CCL5-ODD were measured with the tissue culture $50 \%$ infective dose $\left(\mathrm{TCID}_{50}\right)$ method.

In vitro viral replication assay. Cells in contact-inhibition phase and cancer cells in log-phase were seeded in 6-well plates and infected with the recombinant adenoviruses at a multiplicity of infection (MOI) of 5.0 plaque-forming units (pfu)/cell. Cells were then washed twice with PBS and incubated at $37^{\circ} \mathrm{C}, 1 \% \mathrm{O}_{2}$ for 0,48 or $96 \mathrm{~h}$. Cell lysates were prepared with three cycles of freezing and thawing. Serial dilutions of the lysates were titered in HEK293 cells, with the TCID 50 method, normalized with that at the beginning of infection and reported as multiples.

ELISA for CCL5 expression. In the in vitro experiments, SMMC-7721, BEL-7404 and BEL-7405 were seeded in 6-well plates at a density of $5 \times 10^{5}$ cells per well. To investigate the CCL5 expression in hepatoma cells, SMMC-7721, BEL-7404 and BEL-7405 were infected with SG511-CCL5-ODD at an MOI of 5 pfu/cell in normoxia and hypoxia, respectively. At $72 \mathrm{~h}$ after infection, the supernatants were collected to detect CCL5 expression by ELISA (R\&D).

In vitro cell viability assay. 3-(4,5-dimethylthiazol-2-yl)-2, 5-diphenyltetrazolium bromide (MTT) assay was performed to determine cell viability at various viral MOIs. Cells were plated at a density of $1 \times 10^{4}$ in 96-well plates (Gibco); $24 \mathrm{~h}$ later, cells were infected with SG511-CCL5-ODD at a wide range of MOI from 0.001 to $100 \mathrm{pfu} / \mathrm{cell}$. After 7 days of incubation, cell viability was measured by MTT assay using the non-radioactive cell proliferation kit (Roche Molecular Biochemicals), according to the kit protocol, and the spectrophotometrical absorbance of the samples was read on a microtiter plate reader at $570 \mathrm{~nm}$ in a reference wavelength of $650 \mathrm{~nm}$. The percentage of cell survival was calculated using the formula: Cell survival $(\%)=($ A value of infected cells/A value of uninfected control cell) x $100 \%$. Eight replicating samples were obtained at each MOI and each experiment was performed at least three times.

Transwell chamber chemotactic assay. Serum-free MEM/ $\alpha M$ (containing $2 \times 10^{5}$ cell $/ 200 \mu \mathrm{l}$ ) was added to the upper compartment of the invasion chamber. Conditioned medium $(1 \mathrm{ml})$ was added to the lower compartment of the invasion chamber. The lower compartment of the invasion chamber of the control and the standard group were supplemented with $1 \mathrm{ml}$ serum-free $\mathrm{MEM} / \alpha \mathrm{M}$ and $1 \mathrm{ml}$ containing $1 \mathrm{ng} / \mathrm{ml}$ RANTES serum-free $\mathrm{MEM} / \alpha \mathrm{M}$, respectively. The invasion chambers were incubated at $37^{\circ} \mathrm{C}$ for $24 \mathrm{~h}$, and the inserts and cells on the upper side of the filter were then removed. Cells that invaded the underside of the filter were counted. Each experiment was repeated three times. The values obtained were calculated by averaging the total number of cells from triplicate determinations.

Animal experiments. BALB/c nude mice (nu/nu) were purchased from the Shanghai Experimental Animal Center, Chinese Academy of Sciences. SMMC-7721 cancer cells in $\log$ phase were subcutaneously injected into the right flanks of mice ( $1 \times 10^{7}$ per mouse). Two weeks later, the tumor xenografts were established, 40 mice were randomly assigned to four groups (SG511, AD5/11-CCL5-ODD, SG511-CCL5-ODD and the control group, $\mathrm{n}=10$ mice/group). Tumors were then injected with $100 \mu \mathrm{l}$ control buffer or $2 \times 10^{8} \mathrm{pfu}$ of viruses. The injections were repeated every other day for five times, with a total dosage of $1 \times 10^{9} \mathrm{pfu}$.

Other SMMC-7721 tumor xenograft models were established as mentioned above to evaluate the combined antitumor efficacy of SG511-CCL5-ODD and NK-92. The mice were divided randomly into four groups: I (SG511-CCL5-ODD), II (NK-92), III (SG511-CCL5-ODD+NK-92) and control (10 mice/group). Group I was given a total of $1 \times 10^{9} \mathrm{pfu}$ viruses five times by intratumoral injection, once every other day. The mice in group II received intravenous inoculations of $2.5 \times 10^{7}$ NK-92 cells five times, once every other day. Group III received intratumoral injection of $2 \times 10^{8} \mathrm{pfu}$ viruses in $100 \mu \mathrm{l}$ viral preservation solution and at the indicated time after injection, $5 \times 10^{6}$ NK-92 in $200 \mu 1$ of PBS were administered by intravenous inoculation, the animals received a series of five doses of viruses and NK-92 cells. In the control group, $100 \mu \mathrm{l}$ viral preservation solution [10 mM Tris- $\mathrm{HCl}$ (pH 8.0), $2 \mathrm{mM} \mathrm{MgCl}_{2}$, $4 \%$ sucrose] per mouse per time was injected intratumorally. Tumor volume was estimated with the formula: (maximal diameter) $\mathrm{x}$ (perpendicular diameter $)^{2} \mathrm{x} 0.5$. All animal experiments were performed according to the Guidelines for the Institutional Animal Care and Use Committee of The Second Military University (Shanghai, China).

Immunohistochemistry. Tumor samples wereformalin-fixed and paraffin-embedded and successive sections for H\&E staining and immunohistochemistry were prepared. CCL5-expressing cells were assessed by staining with a goat anti-human CCL5 (R\&D) followed by incubation with a biotin-conjugated rabbit 

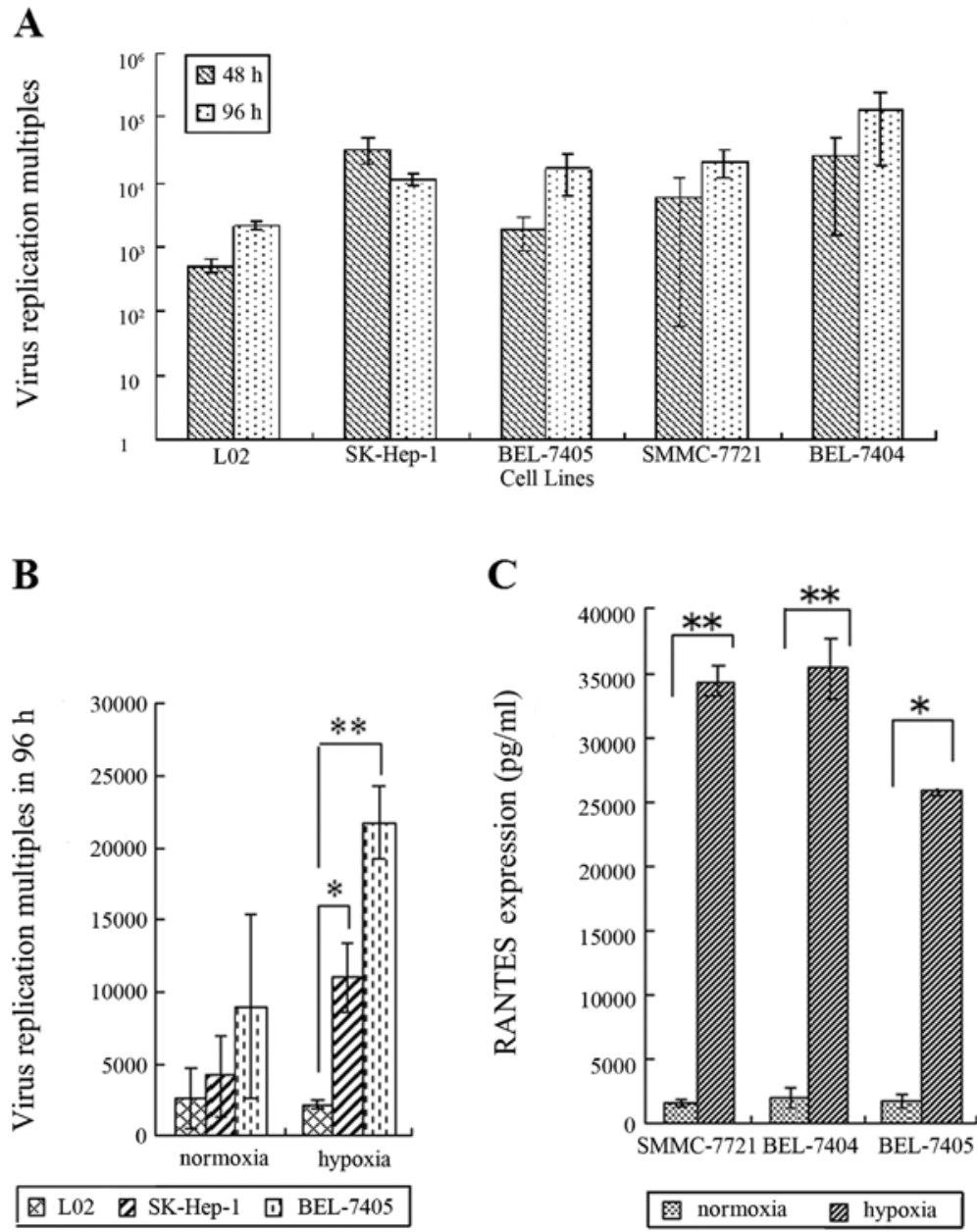

Figure 1. SG511-CCL5-ODD selectively replicates and mediates high expression of RANTES in HCC cells. (A) Selective replication ability of SG511-CCL5-ODD ${ }^{*} \mathrm{p}<0.05 ;{ }^{* *} \mathrm{p}<0.01$. (B) Selective replication ability of SG511-CCL5-ODD in different proportions of oxygen in $96 \mathrm{~h}$. ${ }^{*} \mathrm{p}<0.05 ;{ }^{* *} \mathrm{p}<0.01$. (C) Protein expression of the RANTES gene in different proportions of oxygen. ${ }^{*} \mathrm{p}<0.05 ;{ }^{* *} \mathrm{p}<0.01$.

anti-goat IgG and a horseradish peroxidase (HRP)-conjugated streptavidin (Southern Biotech). NK-92 cells were assessed by staining with a mouse anti-human CD56 (Santa Cruz) followed by incubation with a biotin-conjugated goat anti-mouse $\mathrm{IgG}$ and a horseradish peroxidase-conjugated streptavidin. The positive reaction was visualized with $3^{\prime}, 3^{\prime}$-diaminobenzidine. The sections were examined by two independent investigators for qualitative and semiquantitative analysis.

Statistical analysis. Experiments were performed three times and data are shown as the means \pm SD. Student's t-test was used to interpret the significance of differences between every two groups. ANOVA for repeated measurement experiments was conducted to compare the tumor growth over time between the treated groups and the control group in the animal experiment. $\mathrm{P}<0.05$ was considered to indicate statistically significant differences.

\section{Results}

Adenovirus selectively proliferates and mediates RANTES expression in HCC cells. The Ad5/F11 adenovirus showed a geometrical multiple proliferation in liver cancer cell lines, particularly in BEL-7404 with the proliferation multiple of
250,000 times in hypoxia at $96 \mathrm{~h}$, demonstrating the virus has strong proliferation ability in cancer cells (Fig. 1A). The proliferation multiple of SG511-CCL5-ODD in the normal cell line was very low, showing that SG511-CCL5-ODD has weak proliferation ability in normal cells (Fig. 1B).

With the viral proliferation, Ad5/F11 chimeric adenoviruses express RANTES protein at high levels in SMMC-7721, BEL-7404 and BEL-7405 cells, reaching up to $35427.3 \mathrm{pg} / \mathrm{ml}$ in BEL-7404 cells in hypoxic conditions. Protein expression of the RANTES gene in hypoxia was much higher than that in normoxia in hepatoma cell lines; ODD can effectively regulate RANTES protein expression (Fig. 1C, $\mathrm{P}<0.05$ ).

Cytotoxic specificity of SG511-CCL5-ODD by MTT assay. MTT assay was performed to characterize the specificity of SG511-CCL5-ODD in tumor cells. As shown in Fig. 2, SG511-CCL5-ODD caused significant cytolysis in the Hep3B, Sk-Hep-1 and SMMC-7721 cell lines at a MOI of $0.1 \mathrm{pfu} / \mathrm{cell}, 0.5 \mathrm{pfu} / \mathrm{cell}$ and $1 \mathrm{pfu} / \mathrm{cell}$, respectively. However, normal cells infected with SG511-CCL5-ODD showed a $>50 \%$ cell viability at an MOI of $10 \mathrm{pfu} / \mathrm{cell}$, suggesting that $>10-100$-fold of SG511-CCL5-ODD were needed to kill half of the normal fibroblast cells compared with liver cancer cells (Fig. 2). 


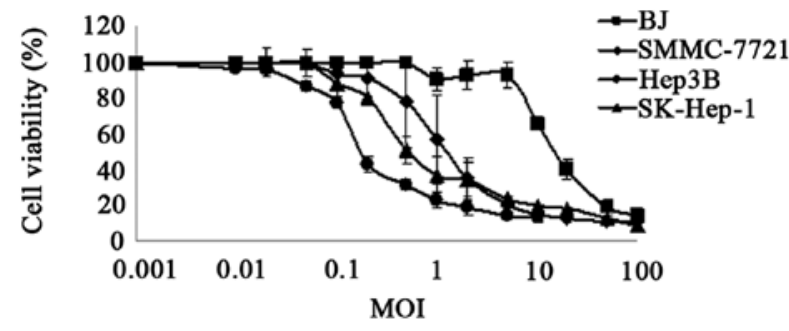

Figure 2. Selective oncolytic effect of SG511-CCL5-ODD on HCC cell lines. At $\mathrm{MOI}=10$, the cell viability was $<30 \%$ in $\mathrm{HCC}$ cells, but $>60 \%$ in normal cells when infected with SG511-CCL5-ODD.

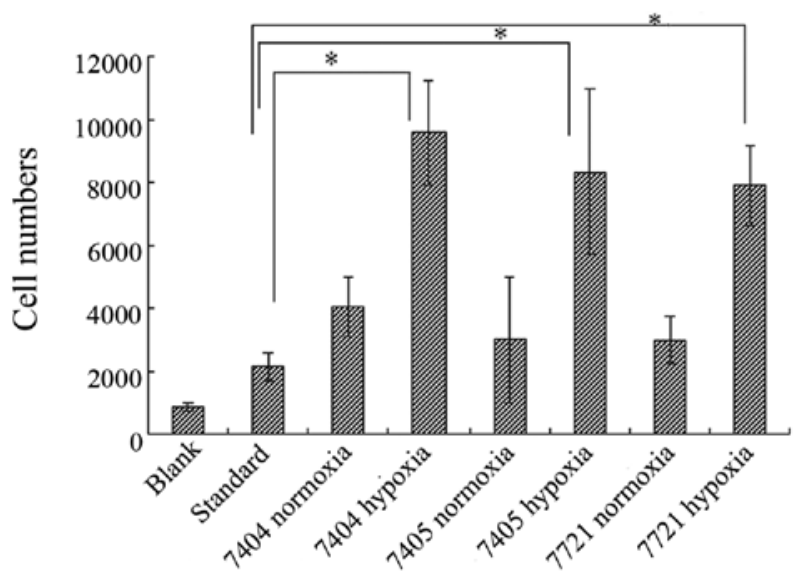

Figure 3. Chemotaxis experiment of CCL5. Chemotactic test results indicated the expressed RANTES can recruit NK-92 cells. In hypoxia, chemotactic capability was more effective than in normoxia $(\mathrm{P}<0.05)$.

Transwell chamber chemotactic assay. The chemokine experimental results showed that, compared with the control group and the standard group which contained RANTES protein at $1 \mathrm{ng} / \mathrm{ml}$ in the lower compartment of the invasion chamber, the RANTES expressed by Ad5/F11 chimeric adenovirus presented the chemotactic activity for NK-92 cells. In hypoxia, the chemotactic effect was higher than in normal oxygen conditions $(\mathrm{P}<0.05)$ (Fig. 3).

Ad5/F11 chimeric adenovirus-mediated RANTES expression exerts antitumor potency in HCC xenograft models. In the SMMC-7721 xenograft models, SG511-CCL5-ODD intratumor treatment significantly inhibited tumor growth compared with the control group from day 14 post-treatment $(\mathrm{P}<0.001)$. Both SG511-CCL5-ODD and AD5/11-CCL5-ODD treatment groups showed stronger antitumor activity than the SG511 group from day 14 post-treatment $(\mathrm{P}<0.05)$ (upper panel, Fig. 4) . Mice were sacrificed after the observation period. Tumors were collected and examined pathologically by H\&E staining. Several large necrotic regions were found in tumors from each group, especially in the SG511-CCL5-ODD-treated group. In the control group, however, cancer cells grew unhindered with only small focal areas of necrosis (Fig. 4A-D).

Antitumor efficacy of SG511-CCL5-ODD combined with NK-92. The antitumor efficacy of SG511-CCL5-ODD combined with NK-92 was evaluated on SMMC-7721 tumor xenografts established in nude mice. Significant reduction of tumor volume was observed in all the treatment groups, with tumor inhibition rates of 51.19, 53.28 and 34\%, respectively, for Group I (SG511-CCL5-ODD), Group II (NK-92), Group III (SG511CCL5-ODD+NK-92), when compared with the control group $(\mathrm{P}<0.05)$ on day 14 after treatment, and $46.15,46.42$ and $32.7 \%$ on day $21,61.04,46.81$ and $31.46 \%$ on day 28 , respectively (Fig. 5A).

Mice were sacrificed 28 days later by cervical dislocation. All tumor samples were examined histologically using H\&E staining (Fig. 5B) and immunohistochemical staining for RANTES (Fig. 5C). In the control group, cancer cells grew abundantly with small foci of necrosis. In the groups treated with replicating viruses or (and) NK-92 cells, several wide areas of necrosis were observed. There were many necrotic foci in tumor tissues of the SG511-CCL5-ODD combined NK-92 groups. Around the necrotic areas, most cancer cells were positive for RANTES expression, but there were no cancer cells positive for RANTES in the NK-92 and control groups.

\section{Discussion}

RANTES (CCL5) is an 8-kDa cytokine, with clear chemotactic activity to the cells which are involved in the immune/inflammatory response, such as lymphocytes, monocytes/macrophages. RANTES can also regulate the function of effector cells. Chemotaxis of RANTES relies on the concentration of RANTES. Therefore, the aggregation of RANTES can enhance its role in chemotaxis. By increasing the local concentration of RANTES, the district can attract the cells by the concentration gradient of the cytokine.

This study successfully constructed a selective replication adenovirus SG511-CCL5-ODD, in which the hTERT promoter drives the Ela gene and the hypoxia response promoter controls the Elb gene. This adenovirus is specifically replicated in tumor cells. ELISA assay was used to detect RANTES protein expression in tumor cells infected with SG511-CCL5-ODD. We found RANTES protein expression was different in both normoxic and hypoxic conditions, when in the same MOI and at the same time. Expression in hypoxia was significantly higher than in normoxia $(\mathrm{P}<0.05)$, confirming that adenovirus SG511-CCL5-ODD in hypoxic conditions has a stronger ability of gene expression. The results proved the RANTES gene under the control of ODD, RANTES protein in normal oxygen conditions is partially degraded.

The chemotaxis test is a method used to test the effectiveness of chemokine. Compared with the control, we found the virus in liver cancer cells could highly express RANTES protein and had a strong chemotactic effect to NK-92 cells. The supernatant of liver cancer cells which was infected by SG511CCL5-ODD was more effective to chemotaxis NK-92 cells in hypoxic conditions. The RANTES protein was confirmed as a strong chemotaxis agent for NK-92 cells. High concentrations of local tumor chemokine RANTES protein attract immune cells around the tumor tissue to maintain a high concentration of immune cells, which is key to cancer biological therapy.

In the liver cancer xenograft model, significant tumor growth inhibition was demonstrated in all the treatment groups compared with the control group. From day 14 after treatment, 

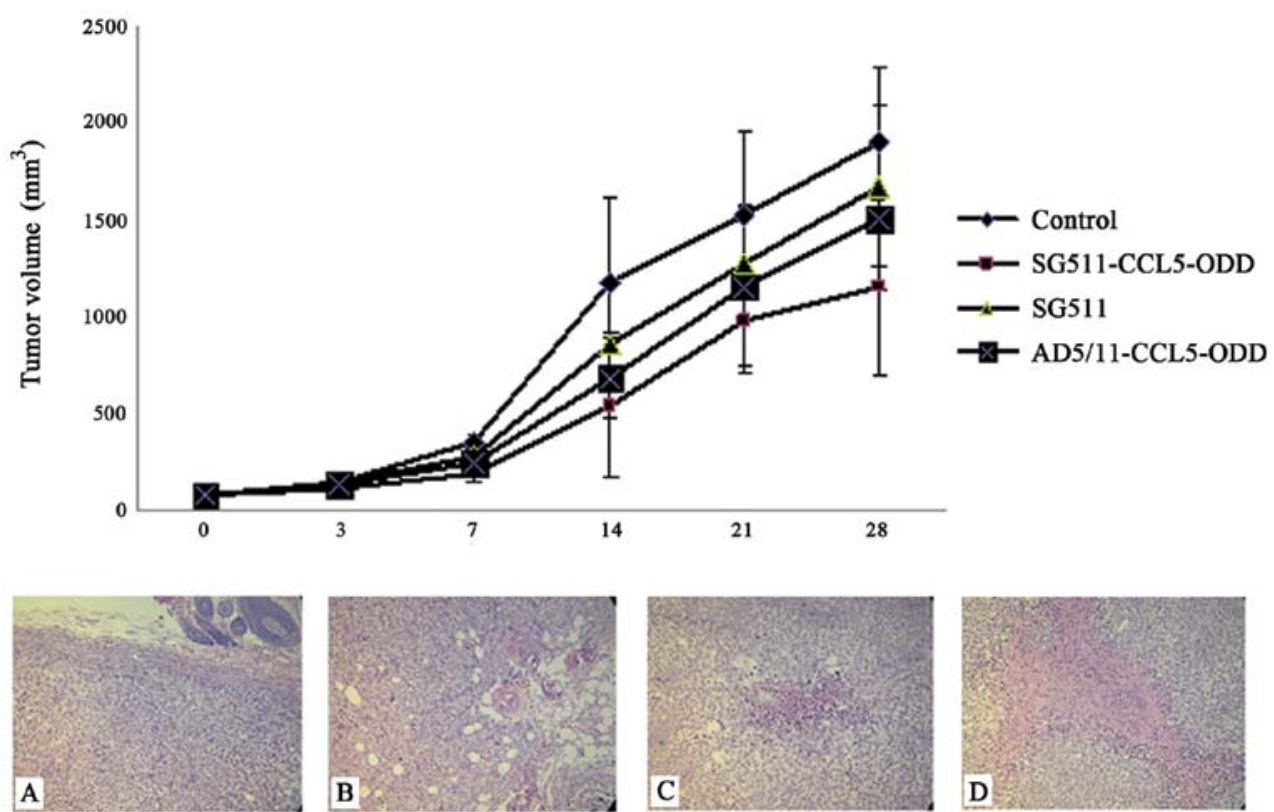

Figure 4. Antitumor efficacy of RANTES in SMMC-7721 tumor xenografts. Mice were given five intratumoral injections to introduce viruses into SMMC-7721 xenografts, one injection every other day with $2 \times 10^{8}$ plaque-forming units/dose/mouse. The potent antitumor effect was shown in all virus-treated groups. SG511-CCL5-ODD showed the best antitumor growth effect. The antitumor effect of SG511-CCL5-ODD and AD5/11-CCL5-ODD was stronger than that of SG511. (A-D) Pathological examination of tumor specimens, magnification x200. H\&E staining showed wide areas of necrosis in tumor tissues of the SG511CCL5-ODD-treated group, but cancer cells grew abundantly in the control group; (A) control; (B) SG511; (C) AD5/11-CCL5-ODD; (D) SG511-CCL5-ODD.

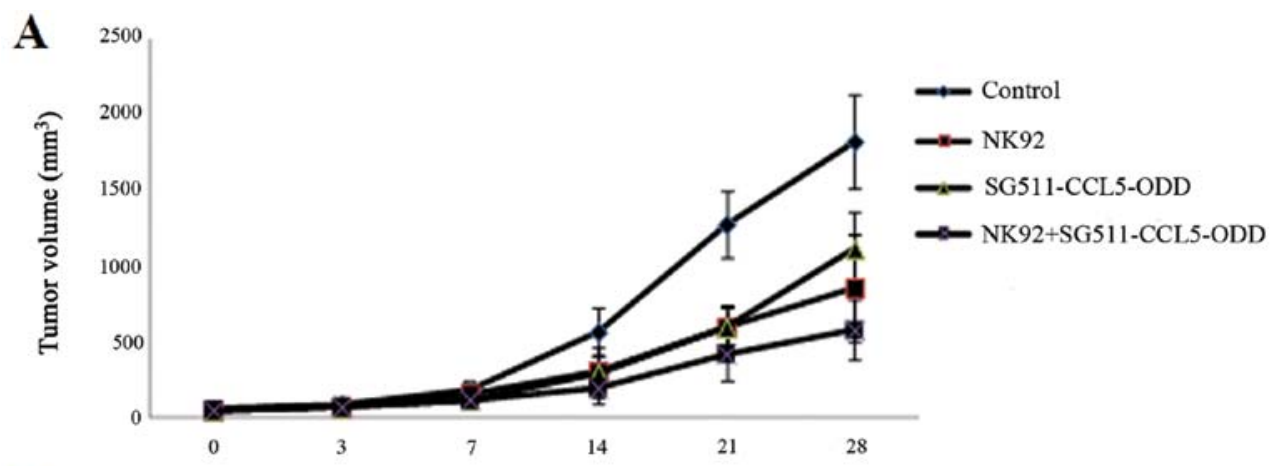

B

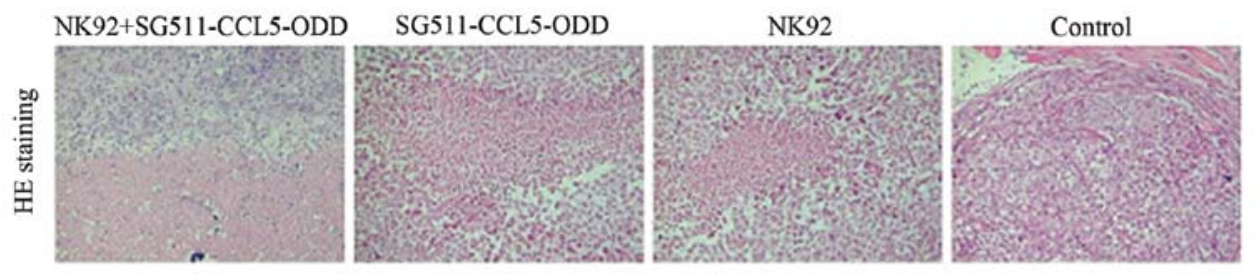

C

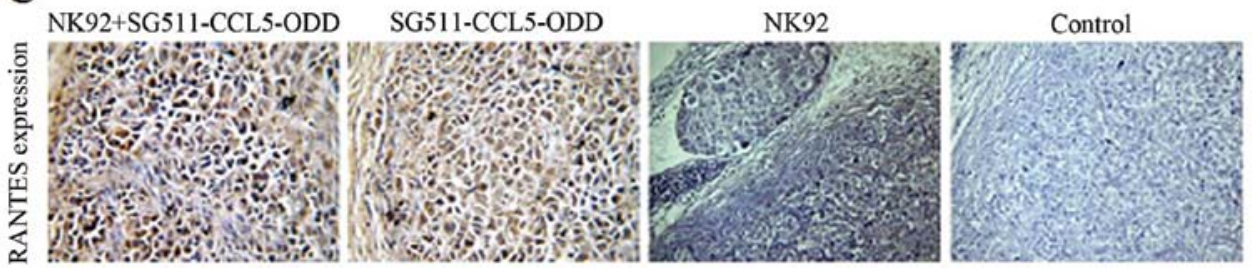

Figure 5. Antitumor efficacy of RANTES combined with NK92 in SMMC-7721 tumor xenografts. (A) Mice were given five intratumoral injections to introduce SG511-CCL5-ODD viruses into SMMC-7721 xenografts, one injection every other day with $2 \times 10^{8}$ plaque-forming units/dose/mouse or given five intravenous inoculations of $5 \times 10^{6} \mathrm{NK}-92$ cells five times, once every other day. The potent antitumor effect was shown in all virus-treated and/or NK92-treated groups. The combined group of SG511-CCL5-ODD and NK92 showed the best antitumor growth effect. The antitumor effect of NK92 was stronger than that of SG511CCL5-ODD. (B) H\&E staining pathological examination of tumor specimens, magnification x200. H\&E staining showed wide areas of necrosis in tumor tissues of the SG511-CCL5-ODD combined with the NK92-treated group, but cancer cells grew abundantly in the control group. (C) The hepatocytes were positive for RANTES protein in mice of the NK92+SG511-CCL5-ODD and the SG511-CCL5-ODD group injected with SG511-CCL5-ODD; magnification x200. 
the tumor volume in the mice treated with SG511-CCL5-ODD combined with NK-92 was suppressed more than that in the mice with any other treatment. After a 4-week treatment, when compared with the control group, the tumor volume was reduced by 68.54 and $53.19 \%$, respectively, in Group III (SG511CCL5-ODD+NK-92) and Group II (NK-92), and Group III (SG511-CCL5-ODD+NK-92) showed more tumor repression than Group II $(\mathrm{NK}-92)(\mathrm{P}<0.01)$. These results indicate that all treatments [including I (SG511-CCL5-ODD), II (NK-92) and III (SG511-CCL5-ODD+NK-92)] inhibited tumor growth and III (SG511-CCL5-ODD+NK-92) is the most efficient agent among them. Therefore, immune cell-viral biotherapy is superior to simple immunotherapy and virotherapy.

\section{Acknowledgements}

This study was financially supported by the Key Program of the National Natural Science Foundation of China (No. 81071850) and the National Science Funds for Distinguished Young Scholars (No. 30925037).

\section{References}

1. Dudley ME, Yang JC, Sherry R, Hughes MS, Royal R, Kammula U, Robbins PF, Huang J, Citrin DE, Leitman SF, Wunderlich J, Restifo NP, Thomasian A, Downey SG, Smith FO, Klapper J, Morton K, Laurencot C, White DE and Rosenberg SA: Adoptive cell therapy for patients with metastatic melanoma: evaluation of intensive myeloablative chemoradiation preparative regimens. J Clin Oncol 26: 5233-5239, 2008.

2. Dudley ME, Wunderlich JR, Shelton TE, Even J and Rosenberg SA: Generation of tumor-infiltrating lymphocyte cultures for use in adoptive transfer therapy for melanoma patients. J Immunother 26: 332-342, 2003.

3. Dudley ME, Wunderlich JR, Yang JC, Sherry RM, Topalian SL, Restifo NP, Royal RE, Kammula U, White DE, Mavroukakis SA, Rogers LJ, Gracia GJ, Jones SA, Mangiameli DP, Pelletier MM, Gea-Banacloche J, Robinson MR, Berman DM, Filie AC, Abati A and Rosenberg SA: Adoptive cell transfer therapy following non-myeloablative but lymphodepleting chemotherapy for the treatment of patients with refractory metastatic melanoma. J Clin Oncol 23: 2346-2357, 2005

4. Wrzesinski C, Paulos CM, Kaiser A, Muranski P, Palmer DC, Gattinoni L, Yu Z, Rosenberg SA and Restifo NP: Increased intensity lymphodepletion enhances tumor treatment efficacy of adoptively transferred tumor-specific T cells. J Immunother 33 $1-7,2010$

5. Rosenberg SA, Yang JC, Sherry RM, Kammula US, Hughes MS, Phan GQ, Citrin DE, Restifo NP, Robbins PF, Wunderlich JR, Morton KE, Laurencot CM, Steinberg SM, White DE and Dudley ME: Durable complete responses in heavily pretreated patients with metastatic melanoma using T-cell transfer immunotherapy Clin Cancer Res 17: 4550-4557, 2011.

6. Ripley RT, Davis JL, Klapper JA, Mathur A, Kammula U, Royal RE, Yang JC, Sherry RM, Hughes MS, Libutti SK, White DE, Steinberg SM, Dudley ME, Rosenberg SA and Avital I: Liver resection for metastatic melanoma with postoperative tumorinfiltrating lymphocyte therapy. Ann Surg Oncol 17: 163-170, 2010.

7. Rosenberg SA and Dudley ME: Adoptive cell therapy for the treatment of patients with metastatic melanoma. Curr Opin Immunol 21: 233-240, 2009.

8. Pittet MJ and Mempel TR: Regulation of T-cell migration and effector functions: insights from in vivo imaging studies Immunol Rev 221: 107-129, 2008.

9. Braun SE, Chen K, Foster RG, Kim CH, Hromas R, Kaplan MH, Broxmeyer HE and Cornetta K: The CC chemokine CK beta-11/ MIP-3 beta/ELC/Exodus 3 mediates tumor rejection of murine breast cancer cells through NK cells. J Immunol 164: 4025-4031, 2000.

10. Hromas R, Cripe L, Hangoc G, Cooper S and Broxmeyer HE: The exodus subfamily of $\mathrm{CC}$ chemokines inhibits the proliferation of chronic myelogenous leukemia progenitors. Blood 95: 1506-1508, 2000.
11. Sharma S, Stolina M, Luo J, Strieter RM, Burdick M, Zhu LX, Batra RK and Dubinett SM: Secondary lymphoid tissue chemokine mediates T cell-dependent antitumor responses in vivo. J Immunol 164: 4558-4563, 2000.

12. Kudo T, Lu H, Wu JY, Graham DY, Casola A and Yamaoka Y: Regulation of RANTES promoter activation in gastric epithelial cells infected with Helicobacter pylori. Infect Immun 73: 7602-7612, 2005.

13. Lebovic DI, Chao VA and Taylor RN: Peritoneal macrophages induce RANTES (regulated on activation, normal T cell expressed and secreted) chemokine gene transcription in endometrial stromal cells. J Clin Endocrinol Metab 89: 1397-1401, 2004.

14. Veillard NR, Kwak B,Pelli G, Mulhaupt F,James RW, Proudfoot AE and Mach F: Antagonism of RANTES receptors reduces atherosclerotic plaque formation in mice. Circ Res 94: 253-261, 2004.

15. Rojas-Ramos E, Avalos AF, Pérez-Fernandez L, Cuevas-Schacht F, Valencia-Maqueda E and Terán LM: Role of the chemokines RANTES, monocyte chemotactic proteins- 3 and -4 and eotaxins- 1 and -2 in childhood asthma. Eur Respir J 22: 310-316, 2003.

16. Chen CJ, Chen JH, Chen SY, Liao SL and Raung SL: Upregulation of RANTES gene expression in neuroglia by Japanese encephalitis virus infection. J Virol 78: 12107-12119, 2004.

17. Oltmanns U, Issa R, Sukkar MB, John M and Chung KF: Role of c-jun N-terminal kinase in the induced release of GM-CSF, RANTES and IL-8 from human airway smooth muscle cells. Br J Pharmacol 139: 1228-1234, 2003.

18. Teichmann JV, Ludwig WD and Thiel E: Cytotoxicity of interleukin 2-induced lymphokine-activated killer (LAK) cells against human leukemia and augmentation of killing by interferons and tumor necrosis factor. Leuk Res 16: 287-298, 1992.

19. Pawelec G: MHC-unrestricted immune surveillance of leukemia. Cancer Biother 9: 265-288, 1994.

20. Dokhelar MC, Wiels J, Lipinski M, Tetaud C, Devergie A, Gluckman E and Tursz T: Natural killer cell activity in human bone marrow recipients: early reappearance of peripheral natural killer activity in graft-versus-host disease. Transplantation 31: 61-65, 1981

21. Cerwenka A and Lanier LL: Natural killer cells, viruses and cancer. Nat Rev Immunol 1: 41-49, 2001.

22. Lanier LL: NK cell recognition. Annu Rev Immunol 23: 225-274, 2005.

23. Drexler HG and Matsuo Y: Malignant hematopoietic cell lines: in vitro models for the study of natural killer cell leukemialymphoma. Leukemia 14: 777-782, 2000.

24. Yan Y, Steinherz P, Klingemann HG, Dennig D, Childs BH, McGuirk J and O'Reilly RJ: Antileukemia activity of a natural killer cell line against human leukemias. Clin Cancer Res 4: 2859-2868, 1998.

25. Gong JH, Maki G and Klingemann HG: Characterization of a human cell line (NK-92) with phenotypical and functional characteristics of activated natural killer cells. Leukemia 8: 652-658, 1994.

26. Reid GS, Bharya S, Klingemann HG and Schultz KR: Differential killing of pre-B acute lymphoblastic leukaemia cells by activated NK cells and the NK-92 ci cell line. Clin Exp Immunol 129: 265-271, 2002.

27. Tam YK,MiyagawaB,Ho VCandKlingemannHG:Immunotherapy of malignant melanoma in a SCID mouse model using the highly cytotoxic natural killer cell line NK-92. J Hematother 8: 281-290, 1999.

28. Tonn T, Becker S, Esser R, Schwabe D and Seifried E: Cellular immunotherapy of malignancies using the clonal natural killer cell line NK-92. J Hematother Stem Cell Res 10: 535-544, 2001.

29. Bergelson JM, Cunningham JA, Droguett G, Kurt-Jones EA, Krithivas A, Hong JS, Horwitz MS, Crowell RL and Finberg RW: Isolation of a common receptor for Coxsackie $\mathrm{B}$ viruses and adenoviruses 2 and 5. Science 275: 1320-1323, 1997.

30. Tomko RP, Xu R and Philipson L: HCAR and MCAR: the human and mouse cellular receptors for subgroup $\mathrm{C}$ adenoviruses and group B coxsackieviruses. Proc Natl Acad Sci USA 94: 3352-3356, 1997.

31. Kim M, Zinn KR, Barnett BG, Sumerel LA, Krasnykh V, Curiel DT and Douglas JT: The therapeutic efficacy of adenoviral vectors for cancer gene therapy is limited by a low level of primary adenovirus receptors on tumour cells. Eur J Cancer 38: 1917-1926, 2002.

32. Matsumoto K, Shariat SF, Ayala GE, Rauen KA and Lerner SP: Loss of coxsackie and adenovirus receptor expression is associated with features of aggressive bladder cancer. Urology 66: 441-446, 2005. 
33. Yamamoto H, Itoh F, Sakamoto H, Nakajima Y, Une Y, Hinoda Y and Imai K: Association of reduced cell adhesion regulator messenger RNA expression with tumor progression in human hepatocellular carcinoma. Int J Cancer 74: 251-254, 1997.

34. Gaggar A, Shayakhmetov DM and Lieber A: CD46 is a cellular receptor for group B adenoviruses. Nat Med 9: 1408-1412, 2003.

35. Hara T,Kojima A,Fukuda H, Masaoka T, Fukumori Y, Matsumoto $\mathrm{M}$ and Seya T: Levels of complement regulatory proteins, CD35 (CR1), CD46 (MCP) and CD55 (DAF) in human haematological malignancies. Br J Haematol 82: 368-373, 1992.

36. Kinugasa N, Higashi T, Nouso K, Nakatsukasa H, Kobayashi Y, Ishizaki M, Toshikuni N, Yoshida K, Uematsu S and Tsuji T: Expression of membrane cofactor protein (MCP, CD46) in human liver diseases. Br J Cancer 80: 1820-1825, 1999.

37. Murray KP, Mathure S, Kaul R, Khan S, Carson LF, Twiggs LB, Martens MG and Kaul A: Expression of complement regulatory proteins-CD 35, CD 46, CD 55 and CD 59-in benign and malignant endometrial tissue. Gynecol Oncol 76: 176-182, 2000.

38. Thorsteinsson L, O'Dowd GM, Harrington PM and Johnson PM: The complement regulatory proteins CD46 and CD59, but not CD55, are highly expressed by glandular epithelium of human breast and colorectal tumour tissues. APMIS 106 869-878, 1998.

39. Vähä-Koskela MJ, Heikkilä JE and Hinkkanen AE: Oncolytic viruses in cancer therapy, Cancer Lett 254: 178-216, 2007.

40. Liu X, Qian Q, Xu P, Wolf F, Zhang J, Zhang D, Li C and Huang Q: A novel conditionally replicating 'armed' adenovirus selectively targeting gastrointestinal tumors with aberrant wnt signaling. Hum Gene Ther 22: 427-437, 2011
41. Xie M, Niu JH, Chang Y, Qian QJ, Wu HP, Li LF, Zhang Y, Li JL, Huang XJ and Ruan GR: A novel triple-regulated oncolytic adenovirus carrying PDCD5 gene exerts potent antitumor efficacy on common human leukemic cell lines. Apoptosis 14: 1086-1094, 2009.

42. Harada H, Hiraoka M and Kizaka-Kondoh S: Antitumor effect of TAT-oxygen-dependent degradation-caspase-3 fusion protein specifically stabilized and activated in hypoxic tumor cells. Cancer Res 62: 2013-2018, 2002.

43. Teicher BA: Hypoxia and drug resistance. Cancer Metastasis Rev 13: 139-168, 1994

44. Kung AL, Wang S, Klco JM, Kaelin WG and Livingston DM: Suppression of tumor growth through disruption of hypoxiainducible transcription. Nat Med 6: 1335-1340, 2000.

45. Helmlinger G, Yuan F, Dellian M and Jain RK: Interstitial pH and $\mathrm{pO} 2$ gradients in solid tumors in vivo: high-resolution measurements reveal a lack of correlation. Nat Med 3: 177-182, 1997.

46. Zhong H, De Marzo AM, Laughner E, Lim M, Hilton DA, Zagzag D, Buechler P, Isaacs WB, Semenza GL and Simons JW: Overexpression of hypoxia-inducible factor 1alpha in common human cancers and their metastases. Cancer Res 59: 5830-5835, 1999.

47. Zhang Q, Chen G, Peng L, Wang X, Yang Y, Liu C, Shi W, Su C, Wu H, Liu X, Wu M and Qian Q: Increased safety with preserved antitumoral efficacy on hepatocellular carcinoma with dualregulated oncolytic adenovirus. Clin Cancer Res 12: 6523-6531, 2006. 